\title{
Structural organization of nascent transcripts and hnRNA molecules in amphibian oocytes
}

\author{
J. Sommerville' \& U. Scheer ${ }^{2}$ \\ ${ }_{1}$ Department of Zoology, University of St. Andrews, St. Andrews, Fife KY16 9TS, Scotland \\ ${ }_{2}$ Division of Membrane Biology and Biochemistry, German Cancer Research Center, D6900 Heidelberg, \\ Federal Republic of Germany
}

\begin{abstract}
Comparisons of relative lengths of lampbrush loops, nascent RNP transcripts and hnRNA molecules from oocytes of amphibia with different $\mathrm{C}$-values show that there is an increasing trend in loop, and transcriptional unit, length with increase in genome size but no increasing trend with respect to RNA contour length. The formation of duplex regions and circles in RNP fibrils indicates that RNA processing may occur within the nascent fibrils. The hnRNA molecules from oocytes of the various amphibia readily form intermolecular duplex structures. These complementary sequences have a low kinetic complexity and are transcribed from highly repetitive sequences distributed throughout the genome. Their possible function is considered.
\end{abstract}

\section{Introduction}

The immediate products of transcription can be viewed in two ways, either as the nascent RNP fibrils seen in Miller spreads $(1,2)$ or as the hnRNA molecules extracted from nuclei. The relationship between these forms is important for the integration of microscopical observation with biochemical data and consequently for a clearer understanding of early post-transcriptional events. Amphibian oocytes are particularly useful in that the germinal vesicles are highly active in transcription (3) and can be easily hand-isolated. Therefore, features of both transcribing chromatin and hnRNA molecules can be studied by direct procedures. Furthermore by using previtellogenic oocytes any analysis is uncomplicated by the transcription of rRNA sequences, since nucleolar activity is negligible at this early oogenic stage.

In this study two features of nascent transcripts and hnRNA molecules have been considered: their relative lengths, which relate to early cleavage events; and their ability to form duplex structures, which relates to the transcription of inverted repeat sequences that may have a regulatory function $(4,5)$. An added complication in examining amphibia, but one that can be turned to advantage for the purpose of studying functional relationships, is that there exists a large range of genome sizes ( $\mathrm{C}$-values as expressed in pgDNA/haploid nucleus) in a series of closely related organisms.

\section{Transcript length and hnRNA length}

The dimensions of transcriptional units have been compared in lampbrush chromosome preparations and in Miller spreads from oocytes of amphibians with different C-values. Oocytes of as near the same previtellogenic stage were used in each instance. As shown in Table 1 there is a general increase in lampbrush loop length and in transcription unit length with increase in genome size. In order to examine whether such an increase is reflected in the lengths of RNA molecules which can be isolated from germinal vesicles, total populations of nuclear RNA molecules were sized by electron microscopic contour analysis. Al- 
Table 1. Comparison of germinal vesicle transcript length and hnRNA length in amphibia with different C-values.

\begin{tabular}{lcccccc}
\hline Organism & \multicolumn{2}{c}{ C-value } & Average loop & \multicolumn{2}{c}{$\begin{array}{c}\text { Transcriptional } \\
\text { unit length }(\mu \mathrm{m})\end{array}$} & \multicolumn{2}{c}{$\begin{array}{c}\text { hnRNA length }(\mu \mathrm{m}) \\
\text { maximum }\end{array}$} & mean \\
\hline Xenopus laevis & 3.1 & 1 & $5-10$ & $2-10$ & 4.7 & 0.56 \\
Triturus cristatus & 23 & 7.4 & $40-50$ & $3-27$ & 10.1 & 1.69 \\
Amphiuma means & 65 & 21 & nd & nd & 6.8 & 1.03 \\
Necturus maculosus & 78 & 25 & $>100$ & nd & 6.1 & 1.04 \\
\hline
\end{tabular}

nd: not determined

though the total nuclear RNA represents both chromatin-bound and unbound forms, previous labeling experiments have demonstrated that as much as half of the nuclear RNA extracted from previtellogenic oocytes is derived from the nascent RNP transcripts of lampbrush chromosomes (6). However, it was found that in Triturus oocytes the range in lengths of hnRNA molecules (up to $7 \mu \mathrm{m}$ ) is much less than the range in lengths of transcriptional units (3-27 $\mu \mathrm{m}$ ). (It should be borne in mind that the lengths of transcriptional units, as well as loops, are minimum estimates that do not take into account any compaction of DNA within the chromatin axis.) In no instances are RNA molecules detected which approach the length of the longest RNP fibrils of average sized transcriptional units. In fact the size distribution of Triturus hnRNA is not very much different from the size distribution of Triturus oocyte poly (A) ${ }^{+}$RNA (data not shown). Since the RNA extraction procedure is gentle and excludes nuclease activity (germinal vesicles are rapidly transferred into ice-cold $70 \%$ ethanol, pelleted, digested with proteinase $\mathrm{K}$ and the RNA sedimented through $5.7 \mathrm{M}^{*} \mathrm{CsCl}$ ), it is concluded that the RNA transcripts are rapidly processed in vivo and that cleavage may occur within the growing RNP fibrils, the linear continuity of the fibrils being maintained by means of protein components. This view is supported by contour length analysis of hnRNA molecules extracted from oocytes of different C-value amphibia which shows that there is little increasing trend with respect to RNA length. It has been demonstrated previously (7) that in cell lines of Drosophila and Aedes, Aedes has a 5-6 fold larger genome than does Drosophila and produces hnR NA which is on average $2-2.5$ fold longer. This is similar to the

situation observed here in the comparison of Xenopus and Triturus, although the results, taken together, favour the view that the hnRNA molecules are already cleavage products.

\section{Formation of stem-loop structures in nascent transcripts}

Previous experiments involving in situ hybridization of denatured DNA probes to nascent RNA transcripts (8) have indicated that processing occurs in the nascent RNP fibril by scission and loss of 5'-terminal RNA sequences. Evidence for excision of RNA sequences from within nascent transcripts comes from an examination of spreads of Triturus oocyte chromatin. Stem-loop and circular RNP structures are readily formed along the nascent RNP fibril ax is and apparently involve the pairing of inverted-repeat sequences to form the neck region.

Stem-loop and circular structures can also be seen frequently in hnRNA spread preparations and the relative dimensions of RNP and RNA forms (Fig. 1) are compatible with the view that they are

RNP RNA

$c=0.40 \pm 0.25 \mu \mathrm{m} \quad c=0.58 \pm 0.89 \mu \mathrm{m}(-1800 \mathrm{n})$
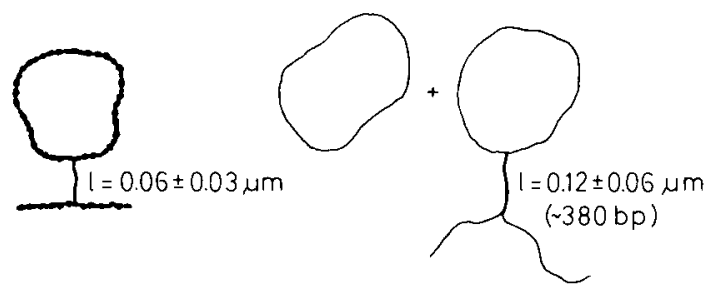

Fig. I. Dimensions of stem-loop structures observed in nascent RNP fibrils and in hnRNA from germinal vesicles of Triturus. (c), circumference of loop; (1), length of stem; ( $n$ ) equivalent length in nucleotides; (bp), equivalent length in base pairs. 
Table 2. Formation of duplex structures in the hnRNA from amphibian oocytes.

\begin{tabular}{llllll}
\hline Organism & C-value & Intramolecular duplex & \multicolumn{3}{c}{ Intermolecular duplex } \\
& $(\mathrm{pg})$ & \% RNA & \% RNA & $\mathrm{R}_{\mathrm{o}} \mathrm{t}^{1} \frac{1}{2}$ & $\mathrm{~T}_{\mathrm{m}}$ \\
\hline Xenopus & 3.1 & 5 & 7.5 & $4 \times 10^{-4}$ & 82 \\
Triturus & 23 & 5 & 10 & $3 \times 10^{2}$ & 79 \\
Amphiuma & 65 & 1.5 & 2 & $2 \times 10^{1}$ & 75 \\
Necturus & 78 & 4.5 & 8.5 & $1.5 \times 10^{-1}$ & 74 \\
\hline
\end{tabular}

derived from the same source. However, the sequences contained within the circles are, as yet, undetermined and further work is required to demonstrate that the electron microscopic observations relate unequivocally to sequence excision in vivo.

\section{Formation of intermolecular duplexes in hnRNA}

In addition to intramolecular hairpin and stemloop structures, when denatured hnRNA from amphibian germinal vesicles is incubated under conditions favoring molecular hybridization (in $0.5 \mathrm{M} \mathrm{NaCl}, 1 \mathrm{mM}$ EDTA, $10 \mathrm{mM}$ Pipes, $\mathrm{pH}$ $6.4,10 \%$ formamide at $56^{\circ} \mathrm{C}$ ) there results extensive intermolecular hybridization, as judged by electron microscopic examination. Intermolecular duplex formation has already been described in detail for HeLa cell hnRNA (9). Here a study was made of the extent of duplex formation, the kinetics of the process and the thermal stability of the duplex regions in hnRNA isolated from the germinal vesicles of different $C$-value a mphibia. In these experiments, total hnRNA, which had been ${ }^{3} \mathrm{H}$-labeled in vivo with all four nucleotide triphosphates, was used and the extent of duplex formation at various times was assayed by counting the ribonuclease-resistant acid-precipitable radioactivity. Thermal stability was assayed by decrease in ribonuclease resistance on increasing the temperature of a solution of annealed hnRNA molecules in $0.1 \times \mathrm{SSC}$. In addition to the biochemical assays, the reactions were checked by electron microscopic examination of spread RNA preparations. The main findings are as follows:

1. In Triturus most of the intermolecular duplex structures fall into a size class of $0.07 \pm 0.015 \mu \mathrm{m}$, which is equivalent to about 220 base pairs, with a less frequent class of $0.64 \pm 0.31 \mu \mathrm{m}$, or 2000 base pairs. In Necturus the duplex regions are generally longer but less well matched.

2. The proportion of RNA sequences capable of rapidly forming duplex structures is different in different $\mathrm{C}$-value organisms (with no trend) but the sequence complexity of complementary repeats increases with C-value (see Table 2).

3. Culture cells from the same organisms (Xenopus and Triturus) give complexity values for RNA complementary repeats which are similar to the oocyte values (not shown).

4. Duplex structures formed in the hnRNA from higher C-value organisms have a lower thermal stability (see Table 2).

When the complementary repeat sequences are isolated, after ribonuclease digestion of annealed molecules, and hybridized with a vast excess of amphibian DNA, it is found that these sequences are transcribed from DNA sequences that are repeated in the genome of Triturus in the order of 2 $\times 10^{3}$ times and in the genome of Necturus in the order of $6 \times 10^{3}$ times (see Table 3). However, the

Table 3. Hybridization of RNA complementary-repeat sequences with excess DNA.

\begin{tabular}{llllll}
\hline $\begin{array}{l}\text { Source of } \\
\text { RNA }\end{array}$ & $\begin{array}{l}\text { Source of } \\
\text { DNA }\end{array}$ & $\begin{array}{l}\text { \% RNA } \\
\text { hybridized* }\end{array}$ & $\begin{array}{l}\mathrm{C}_{\mathrm{o}} \mathrm{t} / 2 \\
\mathrm{RNA} / \mathrm{DNA}\end{array}$ & $\begin{array}{l}\mathrm{C}_{\mathrm{o}} \mathrm{t} 1 / 2 \\
\text { single copy DNA }\end{array}$ & $\begin{array}{l}\text { Gene repeat } \\
\text { frequency }\end{array}$ \\
\hline $\begin{array}{l}\text { Triturus } \\
\text { Necturus }\end{array}$ & Triturus & 62 & 22 & $4 \times 10^{4}$ & $1.8 \times 10^{3}$ \\
Triturus & Necturus & 58 & 25 & $1.4 \times 10^{5}$ & $5.6 \times 10^{3}$ \\
\hline
\end{tabular}

*at a $\mathrm{C}_{\mathrm{o}} \mathrm{t}$ value of $10^{3} \mathrm{M} \cdot \mathrm{sec}$ 
extent of cross-species hybridization is low, indicating that the inverted-repeat sequences transcribed in different amphibia are not homologous.

Taking the various results together, the formation of intermolecular duplexes in Triturus oocyte hnRNA invoves a total sequence complexity of 15000 nucleotides (equivalent to the $R_{o} t 1 / 2$ value of $3 \times 10^{-2} \mathrm{M}$.sec.). Since most of the duplex regions have a length equivalent to 220 nucleotides and the average repeat frequency for each is $2 \times 10^{3}$, then there are about 70 families of different sequence of about 220 nucleotides in length, each transcribed from $2 \times 10^{3}$ genetic loci. Preliminary experiments in hybridizing complementary repeat sequences to lampbrush chromosomes in situ indicate that these sequences have a widespread distribution in the genome.

\section{Transcription during oogenesis: Possible functions}

During amphibian oogenesis, $5-10 \%$ of the genome is transcribed from lampbrush chromosomes irrespective of the C-value of the organism (3). Therefore the analytical complexity of germinal vesicle hnRNA may be as much as $3 \times 10^{8}$ nucleotides in Xenopus, $2 \times 10^{9}$ nucleotides in Triturus and $7 \times 10^{9}$ nucleotides in Necturus. Nevertheless, the cytoplasmic poly(A) ${ }^{+}$RNA of different $\mathrm{C}$-value amphibia is transcribed from single copy genes and summates to a fairly constant sequence complexity of $2 \times 10^{7}$ nucleotides (10). Therefore the vast majority of transcribed sequences, especially in high C-value organisms, has no obvious function. Several possibilities have been suggested for the apparently excessive levels of transcription from lampbrush chromosomes:

1. Materials are stored during oogenesis for use throughout early embryogenesis (11). The stored material may exist as mRNP, as protein or as nuclear restricted sequences.

2. There may be continuous transcription through many sequences with excision of the relatively rare essential sequences. This mechanism appears to be more efficient than precise gene regulation. Evidence is presented in this report that there is extensive processing within the nascent transcripts of high C-value organisms.

3. There may be a physiological function in maintaining a level of transcription proportional to the genomic and nuclear size. For instance, redundant sequences may be used for the simple purpose of swelling the nucleus to increase the number of nuclear pores to assist the exit of essential components such as rRNA sequences (12).

4. There may exist in oocytes an elaborate control mechanism concerned with the preprogramming of activities required for early development. This might occur through nucleic acid interaction $(4,5)$ or through the production of regulatory proteins.

In the present report we have described complementary repeat sequences which are transcribed into the hnRNA of amphibian oocytes and which may have some such regulatory function.

\section{Acknowledgement}

This work was supported by a grant from the Research Council of Great Britain.

\section{References}

1. Miller, O. L., Jr. \& Bakken, A. H., 1972. Karolinska Symp. Res. Methods Reprod. Endocrinol. 5: 155-177.

2. Scheer, U., Spring, H. \& Trendelenburg, M. F., 1979. In: H. Busch (ed.) The Cell Nucleus, Academic Press, New York. Vol. 7, pp. 3-47.

3. Sommerville, J., 1977. Int. Rev. Biochem. 15: 79-156.

4. Scheller, R. H., Constantini, F. D., Kozlowski, M. R., Britten, R. J. \& Davidson, E. H., 1978. Cell 15: 189-203.

5. Davidson, E. H. \& Britten, R. J., 1979. Science 204: 1052-1059.

6. Sommerville, J., 1973. J. Mol. Biol. 78: 487-503.

7. Lengyel, J. \& Penman, S., 1975. Cell 5: 281-290.

8. Old, R. W., Callan, H. G. \& Gross, K. W., 1977. J. Cell Sci. 27: 57-97.

9. Fedoroff, N., Wellauer, P. K. \& Wall, R., 1977. Cell 10: 597-610

10. Rosbash, M., Ford, P. J. \& Bishop, J. O., 1974. Proc. Natl. Acad. Sci. USA 71: 3746-3750.

11. Davidson, E. H., 1976. Gene Activity in Early Development, Academic Press, New York.

12. Cavalier-Smith, T., 1978. J. Cell Sci. 34: 247-278. 